\section{SOI: $1.1 /$ TAS DOI: $10.15863 /$ TAS International Scientific Journal Theoretical \& Applied Science}

Sheeba Rehman
Dr., Assistant Professor at Rai Medical College

Sargoodha, Pakistan ahtasham.ali@gmail.com

p-ISSN: 2308-4944 (print) e-ISSN: 2409-0085 (online)

Year: 2018 Issue: 09 Volume: 65

Published: $24.09 .2018 \quad$ http://T-Science.org
Sara Gulbaz

Dr., Consultant in Indus Hospital Lahore, Pakistan sara.gulbaz@tih.org.pk

Tooba Nawaz

Dr., WMO at Hajj Complex Islamabad, Pakistan nawaztooba@gmail.com

\title{
MISPLACED IUCD, PRESENTATION AND MANAGEMENT
}

\begin{abstract}
Objective: Purpose of this study was to determine various presentations of females with misplaced intra uterine contraceptive device and its management.

Design and setting: This is a cross sectional study which was conducted in Gynecology and Obstetrics department of Doctors Trust Teaching Hospital Sargodha, Pakistan.

Duration: This study was started in January 2018 and completed in July 2018 consisted on 7 months duration.

Patients and methods: In this study 30 female patients with complications of misplaced IUCD were included. These cases presented directly to the study hospital or were referred from other hospitals with different presenting complaints due to misplaced IUCD. An inclusion and exclusion criteria was formed for including patients in the study. A questionnaire was formed for documenting all necessary data of study cases such as age, parity, time duration of IUCD placed etc. These cases were admitted in the ward for treatment. After treatment outcome in each patient was observed. Ethical permission for conducting study was taken from ethical committee of the institution. Consent was also taken from patients in study group and privacy of data was maintained. Data was analyzed on Microsoft office and SPSS software, calculated in the form of percentage and frequency and expressed via tables and charts.

Results: Total 30 cases were studied belonging to different age groups. Range of their ages was 30-43 years with mean age of 36.5 years. Mostly cases were above 30 years of age. Common presenting complaints reported were abdominal pain in 8 cases, dysfunctional uterine bleeding in 5 cases, and missing thread of device while 3 females became pregnant with IUCD and recurrent urinary tract infection due to dislodged device was reported in 4 cases. Different sites of misplaced IUCD were reported such as adherent to uterine wall found in 3 cases, in uterine cavity in 15 cases, inside urinary bladder found in 2 cases, in adenexa In one case, in uterovesicle pouch in 3 cases and in pouch of douglas device was found in 2 cases. It was seen that most common site of dislodged device was intra uterine cavity. These cases were managed according to site of device. Dilatation and uterine exploration was done in females having device in uterine cavity. Other procedures performed were Cystoscopy, Laparotomy and hysteroscopic guided exploration of uterus.

Conclusion: Dislodgement of intra uterine contraceptive device is a much common problem. Most common presenting complaint is abdominal pain. Females should be educated about the use of contraceptive devices its insertion and removal so that complications may be avoided.

Key words: misplaced intra uterine contraceptive device, complications of IUCD, dilatation and curettage.

Language: English

Citation: Rehman S, Gulbaz S, Nawaz T (2018) MISPLACED IUCD, PRESENTATION AND MANAGEMENT. ISJ Theoretical \& Applied Science, 09 (65): 144-148.

Soi: http://s-o-i.org/1.1/TAS-09-65-23 Doi: crostef https://dx.doi.org/10.15863/TAS.2018.09.65.23

\section{INTRODUCTION}

There are many methods of contraception but use of contraceptive devices is commonly used worldwide. This is a very successful method. A contraceptive device is placed in the uterus which prevents pregnancy by physiochemical changes. Females having more number of children usually require contraception method for family planning. By this way a female can postpone pregnancy when she

desires and feels herself physically and mentally prepared for it. This is very useful method. There is slight care in its use because if IUCD is misplaced, it may cause complications. Dislodgement of IUCD is much common leading to abdominal pain, dysfunctional uterine bleeding and recurrent urinary tract infection. If it is misplaced then contraception is failed and female may conceive. This study was conducted to find complications related to misplaced
\end{abstract}


IUCD and its management. If diagnosed early and managed in time then no serious complication occurs. Heavy uterine bleeding, pain, expulsion and uterine perforation are few main complications associated with it. It is very acceptable method in the community because it is cheap, easy to use and it has no effect on sexual activity. It has very low failure rate of $0.001 \%$ so it is very successful method. Using this method mothers can feed their babies safely as there is no harm in it. Intra uterine contraceptive devices are copper devices of $\mathrm{A}$ and Nova $\mathrm{T}$ type. IUCD has a string outside which is used to remove it if we can't se the string it may indicate expulsion of device, broken ring or misplaced device. Such females present with pelvic pain bleeding and pregnancy due to device failure. In this study female patients with complications of misplaced IUCD were included. These cases presented directly to the study hospital or were referred from other hospitals with different presenting complaints due to misplaced IUCD. An inclusion and exclusion criteria was formed for including patients in the study. A questionnaire was formed for documenting all necessary data of study cases such as age, parity, time duration of IUCD placed etc. Misplaced device can be located by uterine examination or using ultrasound. Misplaced device is removed by surgical way either using laparotomy or dilatation and curettage.

\section{Patients and methods}

This is a cross sectional study of observational type. This study was started in January 2018 and completed after 7 months in July 2018. It was conducted in Gynaecology and Obstetrical ward of study institution. In this study female patients with complications of misplaced IUCD were included. These cases presented directly to the study hospital or were referred from other hospitals with different presenting complaints due to misplaced IUCD. An inclusion and exclusion criteria was formed for including patients in the study. A questionnaire was formed for documenting all necessary data of study cases such as age, parity, time duration of IUCD placed etc. These cases were admitted in the ward for treatment. After treatment outcome in each patient was observed. Ethical permission for conducting study was taken from ethical committee of the institution. Consent was also taken from patients in study group and privacy of data was maintained. Data was analyzed on Microsoft office and SPSS software, calculated in the form of percentage and frequency and expressed via tables and charts. According to inclusion criterion those patients were selected who gave history of IUCD use and presented with lower abdominal pain, dysfunctional uterine bleeding and infection of urinary tract or vagina due to misplaced IUCD. Dislodged device was confirmed by examination or radiological investigations. All those patients were excluded from the study which were having other morbidities and IUCD was not found on investigations and examination, on laparotomy other causes of disease found and which patients were not sure of using intra uterine contraceptive device or they were not willing to give proper history.

\section{Results}

During study period 512 cases were admitted in the gynecology ward of study institution and out of them 30 cases were selected with dislodged intra uterine contraceptive device belonging to different age groups. Range of their ages was $20-43$ years with mean age of 31.5 years. There were $2(6.7 \%)$ cases between ages of 20-25 years, $7(23.3 \%)$ were between age of 26-30 years, 6(20\%) were between $31-35$ years, $9(30 \%)$ were between $36-40$ years and $6(20 \%)$ cases were above 40 years of age. Mostly cases were above 30 years of age. Common presenting complaints reported were abdominal pain in $8(26.7 \%)$ cases, dysfunctional uterine bleeding in $5(16 \%)$ cases and in $10(33.3 \%)$ cases thread of device was missing, while $3(10 \%)$ females became pregnant with IUCD and recurrent urinary tract infection due to dislodged device was reported in $4(13.3 \%)$ cases. Different sites of misplaced IUCD were reported such as adherent to uterine wall found in 3 cases, in uterine cavity in $15(50 \%)$ cases, inside urinary bladder found in $2(6.7 \%)$ cases, in adenexa In $1(3.3 \%)$ case, in uterovesicle pouch in $3(10 \%)$ cases and in pouch of douglas device was found in $2(6.6 \%)$ cases. In this study female patients with complications of misplaced IUCD were included. These cases presented directly to the study hospital or were referred from other hospitals with different presenting complaints due to misplaced IUCD. An inclusion and exclusion criteria was formed for including patients in the study. A questionnaire was formed for documenting all necessary data of study cases such as age, parity, time duration of IUCD placed etc. It was seen that most common site of dislodged device was intra uterine cavity. These cases were managed according to site of device. Dilatation and curettage was done in females having device in uterine cavity. Other procedures performed were Cystoscopy, Laparotomy and hysteroscopic guided exploration of uterus. Out of all 33 cases no other disease was found and misplaced IUCD was the primary reason of complications. They all were successfully treated and discharged. Duration of hospital stay was 2-5 days with mean stay was 3.4 days. All operated cases were called for follow up after one week. 


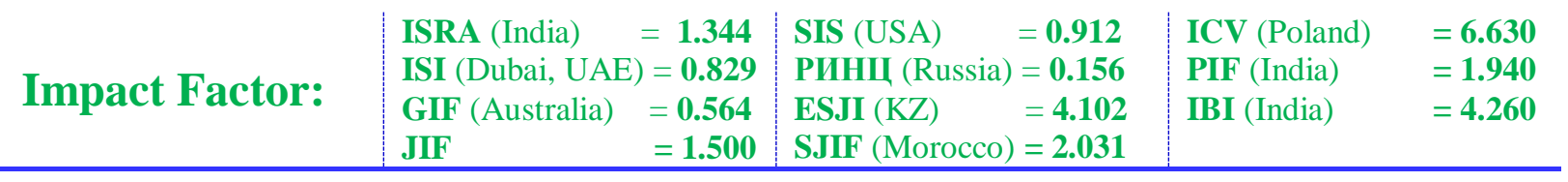

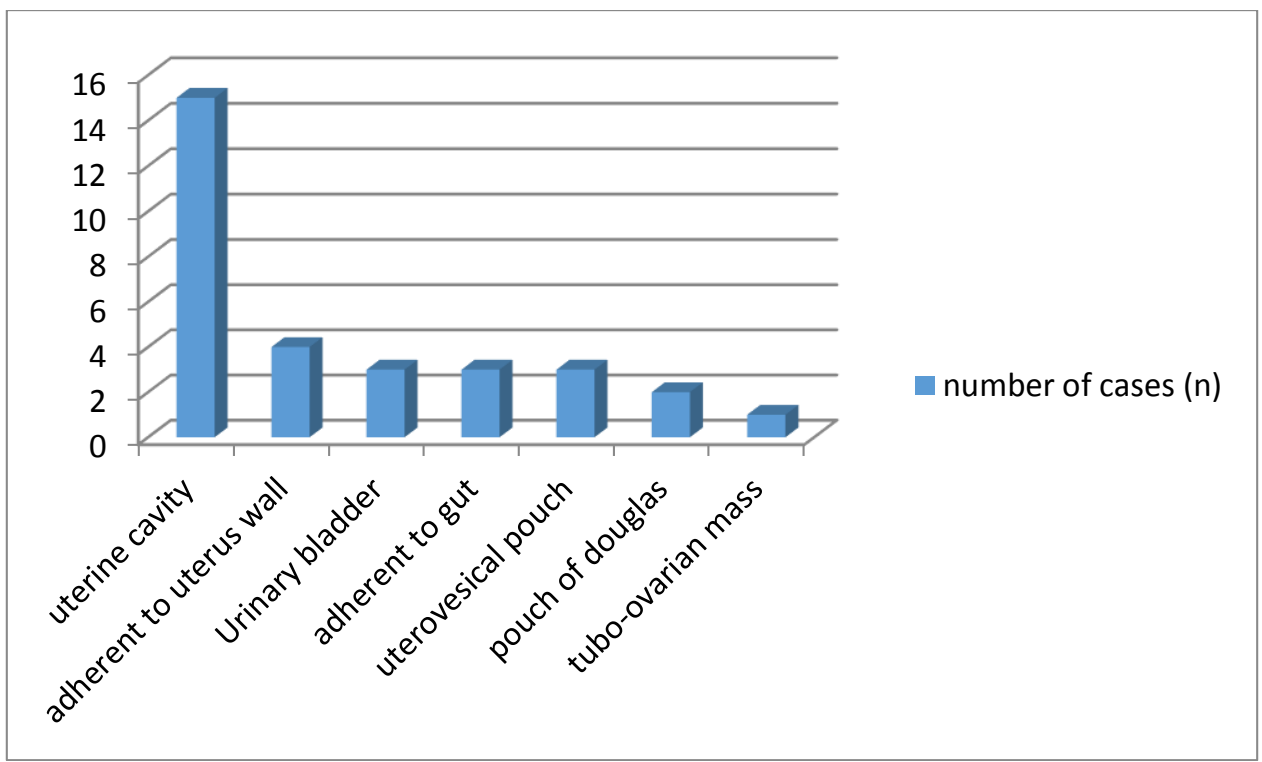

Figure-1 Various sites of misplaced IUCD in study group

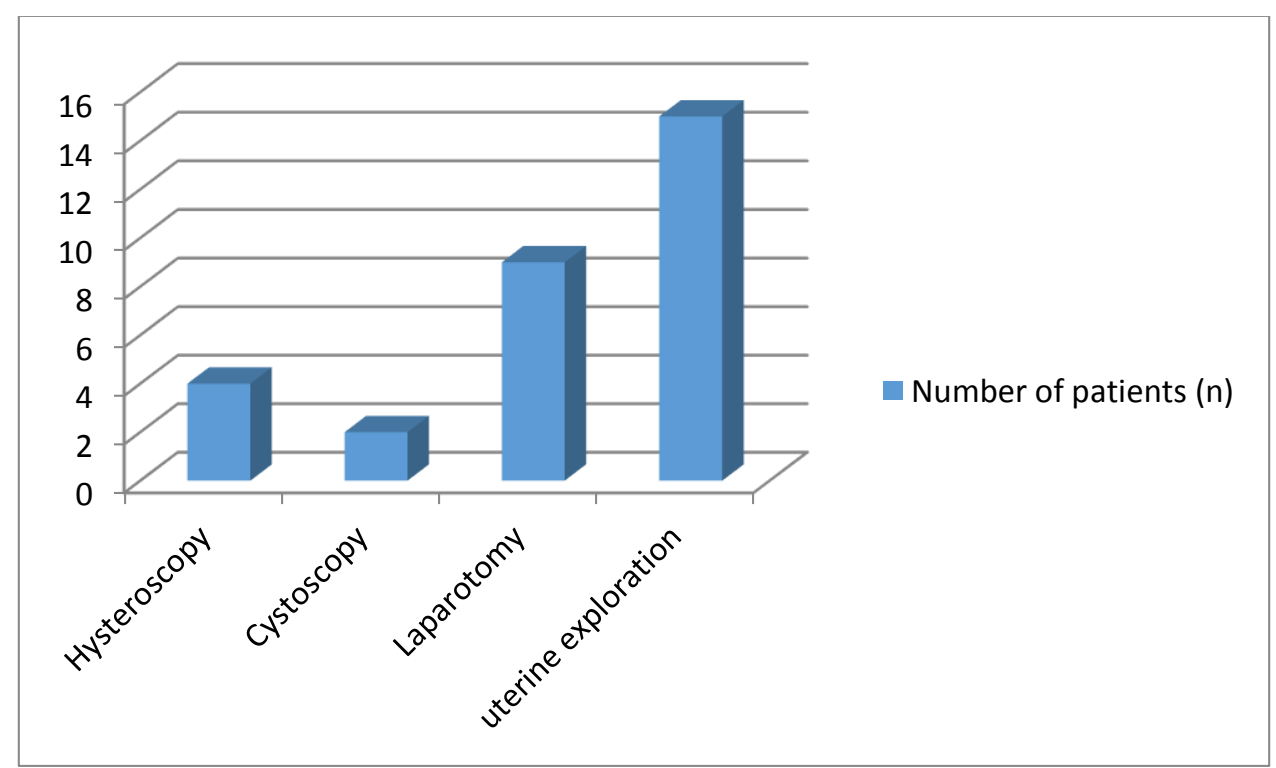

Figure-2 Procedures performed in 30 patients of study group

Presenting complaints in cases of study group

Table-1

\begin{tabular}{|l|c|c|}
\hline \multicolumn{1}{|c|}{ Presenting complaints } & Number of Patients & \% \\
\hline Lower abdominal pain & 8 & 26.7 \\
\hline IUCD thread not found & 10 & 33.3 \\
\hline Dysfunctional uterine bleeding & 5 & 16 \\
\hline Recurrent UTI & 4 & 13.3 \\
\hline Symptoms of pregnancy with IUCD & 3 & 10 \\
\hline
\end{tabular}


Age distribution of study population

\begin{tabular}{|c|c|c|}
\hline Age of patients (years) & N & \% \\
\hline $20-25$ & 2 & 6.7 \\
\hline $26-30$ & 7 & 23.3 \\
\hline $31-35$ & 6 & 20 \\
\hline $36-40$ & 9 & 30 \\
\hline Above 40 & 6 & 20 \\
\hline
\end{tabular}

Table-3

Distribution of patients according to parity

\begin{tabular}{|c|c|c|}
\hline Parity & N & \% \\
\hline $1-2$ & 5 & 16.6 \\
\hline $3-4$ & 11 & 36.7 \\
\hline More than 4 & 14 & 46.7 \\
\hline
\end{tabular}

\section{DISCUSSION}

Intra uterine contraceptive devices are very effective method of contraception with high success rate. It is simple and low effective method. In this study all cases with misplaced IUCD were included which were reported directly to the study institution or were referred from other hospitals. According to a study done by $\mathrm{N}$ Elahi et al common presenting complaint of patients was missing thread of device that was $32.4 \%$. In our study $33.3 \%$ cases presented with the complaint of lost thread of device. During study period 512 cases were admitted in the gynecology ward of study institution and out of them 30 cases were selected with dislodged intra uterine contraceptive device belonging to different age groups. Range of their ages was 20-43 years with mean age of 31.5 years. This is a cross sectional study of observational type. This study was started in January 2018 and completed after 7 months in July 2018. It was conducted in Gynaecology and Obstetrical ward of study institution. In this study female patients with complications of misplaced IUCD were included. These cases presented directly to the study hospital or were referred from other hospitals with different presenting complaints due to misplaced IUCD. There are many methods of contraception but use of contraceptive devices is commonly used worldwide. This is a very successful method. A contraceptive device is placed in the uterus which prevents pregnancy by physiochemical changes. Females having more number of children usually require contraception method for family planning. By this way a female can postpone pregnancy when she desires and feels herself physically and mentally prepared for it. This is very useful method. There is slight care in its use because if IUCD is misplaced, it may cause complications. Dislodgement of IUCD is much common leading to abdominal pain, dysfunctional uterine bleeding and recurrent urinary tract infection. If it is misplaced then contraception is failed and female may conceive. According to study done by $\mathrm{N}$ Elahi and Barsaul et al $28.5 \%$ and $5.5 \%$ respectively cases were reported with IUCD dislodged to peritoneal cavity while in our study $10 \%$ cases had IUCD in peritoneal cavity. This value is comparable to previous results. Common presenting complaints reported were abdominal pain in $8(26.7 \%)$ cases, dysfunctional uterine bleeding in $5(16 \%)$ cases and in $10(33.3 \%)$ cases thread of device was missing, while $3(10 \%)$ females became pregnant with IUCD and recurrent urinary tract infection due to dislodged device was reported in $4(13.3 \%)$ cases. If diagnosed early and managed in time then no serious complication occurs. Heavy uterine bleeding, pain, expulsion and uterine perforation are few main 
complications associated with it. It is very acceptable method in the community because it is cheap, easy to use and it has no effect on sexual activity. Different sites of misplaced IUCD were reported such as adherent to uterine wall found in 3 cases, in uterine cavity in $15(50 \%)$ cases, inside urinary bladder found in $2(6.7 \%)$ cases, in adenexa In $1(3.3 \%)$ case, in uterovesicle pouch in $3(10 \%)$ cases and in pouch of douglas device was found in $2(6.6 \%)$ cases. Similar studies have been done by Betul, Farkhanda and Atakan et al. Uterine perforation is a life threatening complication which is mostly not diagnosed. Such cases should be operated on emergency basis. Early diagnosis and prompt treatment is necessary to avoid complications.

\section{Conclusion}

Intra uterine contraceptive device use is very common due to its high success rate and simple to insert and easy to remove. It is associated with few serious complications when device is misplaced. Early diagnosis and proper treatment leads to complete recovery without any serious morbidity. Dislodgement of intra uterine contraceptive device is a much common problem. Most common presenting complaint is abdominal pain. Females should be educated about the use of contraceptive devices its insertion and removal so that complications may be avoided. Females using IUCD should have proper examination with intervals for the care of contraceptive device.

\section{References:}

1. (2006) What are the most widely used contraceptive methods across the world?" (http://www.ined.fr/en/everything_about_ population/faq/naissances_natalite/bdd/q_text/w hat_are_most_births/birth control). Institut natonal d'etudes demographiques (INED) (2006). Retrieved on 2006-11-16.

2. Anna Glasier. (2007) Contraception. Dewhurst's Textbook of Obstet-rics \& Gynaecology. 7th Ed. 2007 By D. Keith Edmonds. Page 309 - 310.

3. Bhalerao AR, Purandare MC. (1989) Postpuerperal Cu-T insertion. A prospective study. J Postgrad Med. 1989; 35: 70 - 73.

4. Hesham Al-Inany. (2007) Current state of intrauterine contraceptive devices. Middle East Fertility Society Journal. 2007; 12 (01): 8 - 12.

5. (2002) World Health Organization. "The intrauterine device-worth singing about (http://www.who.int/reproductivehealth/hrp/progress/60/news60.html)". Progress in Repro-ductive Health Research (60): 1 -8.

6. Markovitch O, Klein Z, Gidoni Y, et al. (2002) Extrauterine mislocated IUD: Is surgical removal mandatory? Contraception. 2002; 66 (2): $105-8$.

7. Lawal SO, Giwa-Osagie OF, Ogedengbe OK, Usifoh C. (1993) A re-view of referred IUCD related problems in Lagos University Tecahing Hospital. West Afr J Med. 1993 Jul - Sep; 12 (3): $144-7$.

8. Jamelle N. (1991) Retrieval of displaced IUDs in JPMC Pakistan. J Ob-stet Gynaecol. 1991; 4: $60-3$.
9. Andersson K, Ryde-Blomqvist E, Lindell K, et al. (1998) Perforations with intrauterine devices. Report from a Swedish survey. Contraception. 1998 Apr; 57 (4): 251 - 5.

10. Caliskan E, Ozturk N, Dilbaz BO, Dilbaz S. (2003) Analysis of risk fac-tors associated with perforation by intrauterine devices. Eur J Contracept Reprod Health Care. 2003 Sep; 8 (3): $150-5$.

11. Duolao Wang, Altmann Dan R. (2002) Sociodemographic determi-nants of intrauterine device use and failure in China. Human Reproduction. 2002; 17 (5): 1226 - 32.

12. Singhal Savita Rani, Sangwan Krishna. (2005) Multiple intrauterine devices in a pregnant uterus. J Obstet Gynaecol India. Nov/ Dec 2005; 55 (6): 551 - 52.

13. Barsaul M, Sharma N, Sangwan K. (2003) 324 cases of misplaced IUCD: A 5-year study. Trop Doct. 2003 Jan; 33 (1): $11-2$.

14. Ajita J Nawale, Suleman A Merchant, Shyam Sunder E Koteyar, et al. (2000) An unusual case of a misplaced intrauterine contracep-tive device. http://www.bhj.org/journal/2000-4203jul100/ case_522.htm

15. Farkhanada Jabeen, Noor Muhammad. (2002) Intrauterine contracep-tive device perforation. JCPSP. Jul 2002; 12 (7): 445 - 7.

16. AR Jayadeva, AV Lakshmi. (2001) Urinary bladder perforation by an intrauterine contraceptive device. Indian Journal of Urology. 2001; 18 (1): 78 - 79. 